\title{
Impact of High-Frequency Trading on the Stock Returns of Large and Small Companies in the Tehran Stock Exchange
}

\author{
Ahmad Sarlak ${ }^{1} \&$ Zahra Talei $^{2}$ \\ ${ }^{1}$ Faculty of Economic Islamic Azad University of Arak, Iran \\ ${ }^{2}$ Master of Accountancy, Islamic Azad University of Arak, Iran \\ Correspondence: Zahra Talei, Master of Accountancy, Islamic Azad University of Arak, Iran. E-mail: \\ mahtab2002@yahoo.com
}

Received: January 24, 2016

Accepted: February 25, 2016

Online Published: March 25, 2016

doi:10.5539/ijef.v8n4p216

URL: http://dx.doi.org/10.5539/ijef.v8n4p216

\begin{abstract}
The main objective of this study is to evaluate the effect of high-frequency trading on stock returns of the Exchange market in Tehran Stock Exchange. The research methodology in this study is in terms of the purpose, functional and in terms of the method of data collection, descriptive and in terms of the type, solidarity.

Statistical society of this research is all companies in the Tehran Stock Exchange which in the past two years had been active in the stock market. In this study, companies are divided into two categories: large and small companies. Large companies that their assets logarithm is greater than the average total sample and small companies that their assets logarithm is less than the average total sample. To collect information has been used from the financial statements of accepted companies in Tehran Stock Exchange.

MATLAB software has been used for data analysis.

Used tests in this study are include (DF) Dickey-Fuller test, (ADF) Generalized Dickey-Fuller test, Phillips-Perron test, and time series methods. The results of this study show that the dynamics of stock returns of the Tehran Stock Exchange are non-linear functions and high Frequency trading of the large companies affect the turnover of small companies. As a result, volume of the high-frequency trading and the returns of small and large companies are different from each other.
\end{abstract}

Keywords: high-frequency trading, MS- EGARCH, stock returns, stock exchange, assets log

\section{Introduction}

There is a direct relationship between countries economic progress and expansion of the Exchange market; therefore, Exchange is a kind of financial market which in that, the capital is subject to supply and demand and it is a plan to divert a lot of country resources from the provision of goods and consumed services into the production of capital goods. In other words, Exchange by encouraging people to invest their savings, collects capitals and provides the background necessary for growth and development of the country economic (Souri 1392). Since, these markets play a constructive role in the allocation of resources and the national capital, so their desirability will be for the economic development of society. People try at the first to gather information about companies listed on the Exchange and then take action to buy or sell shares. (Namazi, 1384).

In today's competitive world, creating value and wealth creation for shareholders is one of the main objectives of each individual and firm of the investor or investee. Investors want to increase their capital day by day and to maximize it, that's why they are looking for investment opportunities that create more wealth for them. (Bashiri Manesh, 1385).

Some policymakers of the capital markets believe that high-speed trading (HFTs ) are one of the main causes of the financial crisis which in the period from 2007 to 2009 has been located. This view along with the sudden drop in stock markets the United States at the sixth of May 2010, that the "Sudden falls" was named, led to further examine the required fields for review of this relatively new method in stock trading. HFTs used as a risk management tool to strengthen the cash and derivatives markets. This means that the major intermediaries in the sale, along with specialized companies of capital markets spend huge amounts to create the required technologies to meet growing demand. (Slepaczuk \& Zakrzewski, 2010). 
Some researchers believe that high-speed trading will cause alternative rapid profitability in the market. In other words, investors can immediately buy and sell the stocks at a fair price and affect the daily market and also control in some cases. But some critics believe that HFT does not change the market.

So, academic studies are mainly concentrated on the effect of high-speed systems on the liquidity. Liquidity is not only related to the speed of execution (delay) and the gap between price of supply and demand, but also consider the depth and strength of the markets. (Taylor \& Areal, 2002).

Moreover, to be successful stock trading in the capital market, estimating the realized volatility against implied volatility is essential; But before the future volatility can be predict, should be measured is what happened in the past. For this purpose, structure and properties of volatility must be considered. Measuring volatility and prediction of their distribution in trading is necessary, but not sufficient. Determining policy of "swing-making" in the trading is not always a good idea (The purchase of shares, when volatility are the descending and show the lowest level of market prices and sale of shares, when volatility are the ascending and show the highest level of market prices). All predictions must be completed by fundamental analysis. Markets based on containers to evolving law in the economics are very complex and interdependent and all measurements and predictions should be done in the context of their time trading environment. Measuring volatility is not the similar to measuring the price. The volatility of the moment are imperceptible and to unfold need over time. Poon in his research to predict volatility introduced over 100 source, which reflects the required complexity of the volatility situation in the capital market. (Poon, 2005).

Accordingly, the main issue of this study is that high-frequency trading what effect will have on the stock returns of large and small companies in the Tehran Stock Exchange? This paper has been set in 5 parts, in the second part, the theoretical; in the third part, empirical foundations; in the fourth, research methods and model estimation; and in Part V, the obtained conclusions and recommendations of the study are presented.

\section{Theoretical}

Volatility of stock returns indicate changes around of the mean and show price changes of financial instruments over time. Trading of the moment also do a short-term forecast of the market based on trading records and trying to create volatility in the prices to achieve profitability. In addition, the diagnosis of liquidity by sending a small order and check that whether someone receives it or not begins, if the order was implemented can predict that a larger order is behind it. The order was sent with a trading algorithm that from the most obvious examples can be cited to the iceberg method. In 2009, AITE Group also reported that companies in this area have participated in 73 percent of the stock market trading. High-frequency trading is a word that have been used recently to describe a subset of algorithmic trading. This is a new concept and still there is no consensus among the university community and the capital market for its definition. TABB Group which is a research firm and study and report on the global capital market, high frequency trading has been defined as:

"Fully automated trading strategies that attempt unbalanced conditions in the market liquidity or on the prices inefficiency in the short term was benefited". In December 2009, at the high-frequency trading conference in the US, this type of transactions were defined as follows:

"Systematic trading models based on numerical / mathematical models with fractions of seconds to less than one day holding period". From this definition can be clearly understood that this method is very different from the long-term investments. Strategies of trading that are used in the high-frequency trading (providing liquidity), can be categorized in this way:

- Market-building;

- Moment transactions;

- Identify liquidity;

- Simultaneous buying and selling.

Market-building and providing liquidity is looking to get more profit from small gaps between the announcements of buying and selling shares: Login to buy and sell positions and leaving them in a fraction of a second (A millisecond to a microsecond) at the simultaneous buying and selling, traders are looking maximum utilization inefficiencies in prices until with two simultaneous buying and selling on the two of shares which have unusual prices, created liquidity. This needs to feed data quickly and to publish from the moment of receiving market data, send information, receive confirmation of the acceptance and implementation or cancellation order, latency must be very short or even zero. The moment trading predict the short-term market trends based on the records of transactions and attempts to reach profitability by creating volatility in the prices. 
Liquidity diagnosis is an interesting technique, and acts in this way: First, small orders are sent to see whether someone receives it. If the order is executed, then can be assumed that there is a larger order. So, the original order is sent with a trading algorithm. One example of these algorithms is the method of the iceberg. The use of high-frequency trading is increasing. In 2009, AITE Group has reported that active companies in this area have participated in 73 percent of the stock market trading. Diagram 1 shows the relationship between traditional trading, algorithmic trading and high frequency trading.

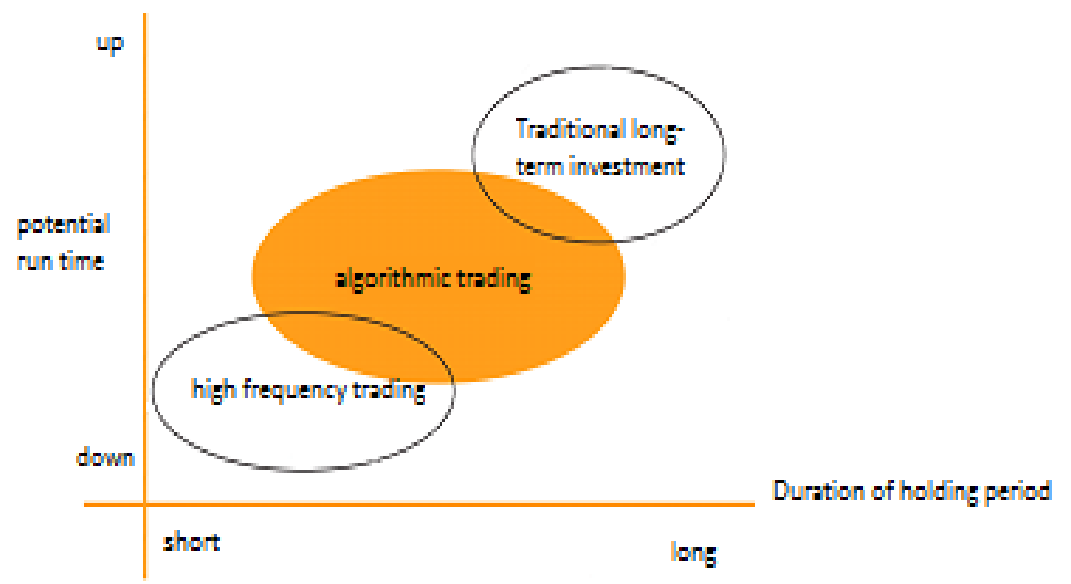

Figure 1. Relationship between traditional trading, algorithmic trading and high frequency trading

\section{Empirical Foundations}

Literature records is divided into two categories. The first part is about the instability of the stock market in different countries and the second part is related to history of the MS-EGARGH method. Economic instability caused by several factors such as the decline in production and sale of oil, high rates and instability of liquidity, stressful foreign relations. Economic instability, in addition to instability of the key and important prices of economic includes many items such as stock market volatility. Therefore, many studies have investigated the instability and volatility of the stock market in different countries that can be pointed to the following: New York stock market volatility (Kmjl \& Hnchl, 1992), Stock market fluctuations and risk premium volatility (Koradi et al., 2009), china's stock market volatility and fall in 1987 (Chaudhry, 1996), The relationship between stock market instability and macroeconomic instability (Morley, 2002), Stock returns, volatility and the global financial crisis in the emerging markets of Nigeria (Rufus \& Ydvjy, 2009), Dynamic Analysis of the Indian stock market (Tyrypaty et al., 2010), The relationship macroeconomic instabilities with evidence of China (Wang, 2011), Evaluate the effect of returns and volatility of stock markets in four countries: Australia, America, Britain and Singapore (Karo Nanatak, 2009), The relationship between the stock markets of China and Hong Kong and America (Lee, 2007), The performance of different GARCH models to predict market risk (Su \& Yu, 2006), Compare Monte Carlo simulation and GARCH model to predict the value at risk (Hefner \& Rumbast, 2004), Evaluate the conditional heterogeneous variance models in time series of the stock returns (AK Giray, 1989), Evaluate the relationship between oil market volatility and stock prices to France, Britain, and Japan (Alloy \& Jamazi, 2010), Study of the long-term relationship and asymmetrical relationship between the Exchange rate and stock prices in Japan and Taiwan (Yu \& Nie, 2009), The relationship between market of currency and stock in areas of East Asia (Flavin et al., 2008), The dynamic relationship between volatility of the stock prices and Exchange rates in emerging countries (Valid et al., 2011). Also in Iran's stock market which is affected by many economic oscillator factors, research has been conducted that can be pointed to the following:

The effects of the financial crisis the West over Tehran Stock Exchange (Taghavi \& others, 1389), The effect of Exchange rate fluctuations on the Iran's stock market volatility (Pedram, 1389), Assessing the effectiveness of risk analysis model and GARCH econometric model to predict the market risk in the Tehran Stock Exchange (Fallah Shams, 1389), Experimental test of stability, predictability and volatility in the capital markets of the Persian Gulf countries (Dadgar \& RamzYari, 1391), Evaluate variability price of gold coins in Iran (Delavari \& Rahmati, 1389), Studying the volatility trend of the Tehran Stock Exchange (Al Omran, 1391), Assessing value at risk CVaR conditional using symmetric and asymmetric conditional heteroskedasticity models in gold and oil market (Fallahpour et al., 1393), Evaluate the dynamics of the Tehran Stock Exchange using the EGARCH-M 
model in the Markov Switching average (Raei, Mohammadi, \& Sarenj, 1393), Studying the relationship between the stock markets of Iran, America, Turkey and Malaysia (AbouNoori \& Abdullah, 1390), Evaluate simultaneously leverage effect and volatility feedback in the stock market Tehran (Abounoori \& Motameni, 1385), Studying the relationship between macroeconomic variables and stock returns in Tehran Stock Exchange (Samadi \& Bayani, 1390).

\section{Methodology and Model Evaluation}

The present study method in terms of aim is practical because the results would predict stock returns. In addition, the present study in terms of data collection method is descriptive - correlation and the relationship between variables using regression model has been examined.

Statistical society of this study is all companies listed in Tehran Stock Exchange. The study sample is consists of active companies of Tehran Stock Exchange during 1392 and 1393. Companies surveyed in terms of the assets logarithm were divided into two groups: large and small companies. Assets logarithm of the large companies is greater than median of total sample and assets logarithm of the small companies is less than the median of total sample. The number of large companies, 74 and small companies, 75 were considered. To collect data has been used from Rahavard Novin software.

To show the high frequency trading on the Stock Exchange has been used from the 5-minute data price index of Tehran Stock Exchange (TEPIX). In addition, using the following equation, the logarithm of the percentage ratio of price index of Tehran Stock Exchange in each period compared to the previous period is considered as stock returns of the Tehran Stock Exchange (Alavi \& Jamazi, 2008).

$$
r_{t}=100 \times \ln \left(\frac{\text { TEPIX }_{t}}{\text { TEPIX }_{t-1}}\right)
$$

The t-index is a 5-minute period. In the following, we will introduce estimation method.

- Markov switching E-GARCH model ( MS-EGARCH )

At the First, we define a model EGARCH $(1,1)$ introduced by Nelson (1991) in the form of equations (1) and (2) for $\mathrm{y}_{\mathrm{t}}$ :

$$
\begin{gathered}
y_{t}=f\left(x_{t} ; \vartheta\right)+\varepsilon_{t} \varepsilon_{t} / I_{t-1} \rightarrow D\left(0, h_{t}\right) \\
\ln \left(h_{t}\right)=\omega_{0}+\varphi\left[\left|\frac{\varepsilon_{t-1}}{\sqrt{h_{t-1}}}\right|-\sqrt{2 / \pi}\right]+\beta \ln \left(h_{t-1}\right)+\delta \frac{\varepsilon_{t-1}}{\sqrt{h_{t-1}}}
\end{gathered}
$$

In equation (1):

$f\left(x_{t} ; \vartheta\right)$ : the conditional average.

$\mathrm{x}_{\mathrm{t}}$ : a vector of explanatory variables $\mathrm{M}$ which may include $\mathrm{y}_{\mathrm{t}} \mathrm{s}^{\prime}$ interval.

$\varphi:$ a $(\mathrm{M} \times 1)$ vector of the parameter.

$\mathrm{I}_{\mathrm{t}-1}$ : a data set that contains all available information at time $(\mathrm{t}-1)$.

And $\varepsilon_{\mathrm{t}}$ : an error term when based on the equation (2), the conditional variance will follow the EGARCH $(1,1)$ process

D: It generally uses t distribution introduced by Bollerslev (1987).

$\mathrm{h}_{\mathrm{t}}$ : as estimated conditional variance is strictly positive and does not need to non-negative constraints used in estimating the model GARCH.

Equation (2) shows an asymmetric effect of negative news on the variance. According to Black (1976) and Nelson (1991), stock market volatility are influenced by the rise and fall of asymmetrical stock prices. Asymmetric effect in the volatility is captured by $\gamma$ coefficient. Taking into account this coefficient to correct the problem of GARCH models by Lamoureaux and Lastrappes (1990) was introduced; According to their study, higher degree of stability shown by standard GARCH process may be due to structural failure fraud and error. Hamilton and Susmel (1994) by running a Markov switching ARCH model (SWARCH) on the weekly data from the UK stock returns, confirmed the strong views of regime changes in the ARCH process. In addition, they claimed that taking into account of regime changes is led to a significant reduction in the stability degree of volatility between the errors. In this regard, Hamilton and Susmel (1994) in the framework of regime change model modified the conditional variance function with the assumption that the conditional variance depends on economic conditions. In the following, we will examine descriptive and inferential statistics of the survey data. 
Table 1. Descriptive statistics indexes of the TEDPIX

\begin{tabular}{cc}
\hline Average & 0.005957 \\
\hline Median & 0.002447 \\
Maximum amount & 0.009207 \\
Minimum amount & 0.000000 \\
Standard deviation & 0.250397 \\
Skewness & 1.105286 \\
Elongation & 4.780318 \\
j-b statistics & 936.8645 \\
Odds & 0.000000 \\
\hline
\end{tabular}

Source: Researcher calculations.

Results Table 1 shows that the elongation of the TEDPIX (Exchange Returns Total Index) is higher than the normal distribution elongation and its skewness is to the right; But according to the $\mathrm{j}$-b statistics and its significance level is observed that series probability distribution of the TEDPIX is not normal and possibly, skewed distributions such as EGARCH to predict the series have the explanatory ability higher than GARCH. In the following, data distribution method related to small and large companies on the Stock Exchange data is displayed. According to the evaluation results of the standardized data distribution function based on the Monte Carlo method can be seen that by moving from large corporations to small businesses, changes range is increased. In other words, the nature of the data distribution of large and small companies is different.

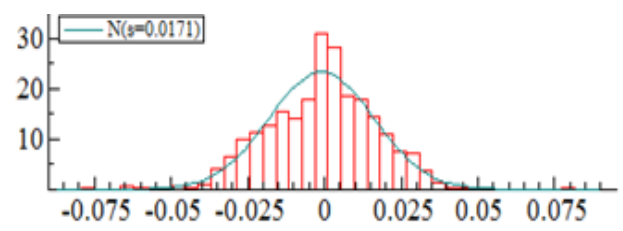

Figure 2. Distribution of returns data of the small companies in the Tehran stock exchange

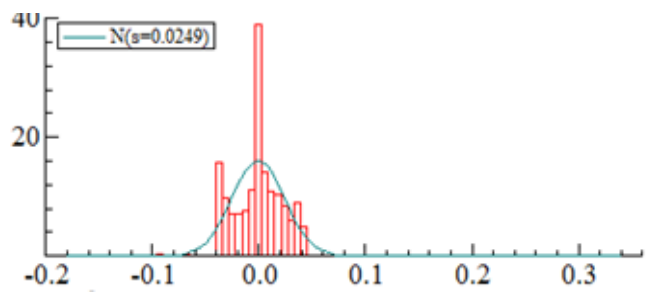

Figure 3. Distribution of returns data of the large companies in the Tehran stock exchange

By comparing results of the diagrams 2 and 3 can be seen that volatility and changes range in large companies is less than small companies. In other words, small companies more than large companies will experience returns volatility. Therefore, due to the different nature, differences behaviors of the large and small companies looks correct. In following, to avoid spurious evaluated regression of the confidence have examined the stability situation of time series of the TEDPIX.

Table 2. Results of stability test on the variables level of model

\begin{tabular}{ccccccc}
\hline & \multicolumn{2}{c}{ Dickey Fuller } & \multicolumn{2}{c}{ Generalized Dickey Fuller } & \multicolumn{2}{c}{ Phillips-Perron } \\
\hline & Statistics & Critical quantity & Statistics & Critical quantity & Statistics & Critical quantity \\
& & $(5 \%)$ & & $(5 \%)$ & & $(5 \%)$ \\
TEDPIX & -13.22 & -2.86 & -5.18 & -1.94 & -53.90 & -2.86 \\
\hline
\end{tabular}

Source: Researcher calculations.

According to results of the Table 2, variable of TEDPIX at the $1 \%$ level is stable and thereby ensure that the regression results will not lead to spurious regression. 
It should be noted since the aim of this study is to investigate the effect of behavior shock of large companies on the behavior of small businesses through the mechanism of high-frequency trading, stationary of the research data can not be an obstacle to achieving this goal; But increase at the level of uncertainty and volatility in stock returns could lead researchers to this goal. Accordingly, in the following discussion will be studied uncertainty in the TEDPIX data and finally, examines the impact of big companies behavior on this uncertainty.

Table 3. Estimate the ARIMA time series model of the TEDPIX

\begin{tabular}{cclcc}
\hline Variable & Coefficient & Std.Error & t-Statistic & Prob. \\
\hline C & 0,306793 & 0,018801 & 16,41801 & 0,0000 \\
AR(1) & 0,493373 & 0,365943 & 1,348224 & 0,1777 \\
AR(2) & 0,472459 & 0,390267 & 1,210605 & 0,2262 \\
AR(3) & $-0,024750$ & 0,045488 & $-0,533106$ & 0,5864 \\
AR(4) & 0,016441 & 0,025952 & 0,633528 & 0,5264 \\
AR(5) & 0,013559 & 0,023133 & 0,586118 & 0,5578 \\
AR(6) & $-0,042791$ & 0,024647 & $-1,809590$ & 0,0705 \\
AR(7) & 0,024378 & 0,029875 & 0,4340 \\
AR(8) & 0,031666 & 0,029378 & 0,782521 & 0,2812 \\
AR(9) & $-0,047038$ & 0,023212 & 1,077887 & 0,0428 \\
AR(10) & 0,002011 & 0,029552 & $-2,026425$ & 0,9257 \\
AR(11) & 0,002285 & 0,025213 & 0,068065 & 0,9278 \\
AR(12) & 0,012040 & 0,023566 & 0,090635 & 0,6095 \\
AR(13) & $-0,000419$ & 0,024162 & 0510888 & 0,9862 \\
AR(14) & $-0,021307$ & 0,023595 & $-0,017336$ & 0,3666 \\
AR(15) & $-0,009132$ & 0,021672 & $-0,904048$ & 0,6735 \\
AR(16) & $0,-48364$ & 0,020368 & $-0,421475$ & 0,0176 \\
MA(1) & $-0,369989$ & 0,366181 & 2,374440 & 0,3124 \\
MA(2) & $-0,508698$ & 0,345422 & $-1,010399$ & 0,1410 \\
\hline R-squared & 0,080367 & Mean dependent var & $-1,472686$ & 0,005957 \\
Adjusted R-squared & 0,074361 & S.D.dependent var & & 0,250840 \\
S.E. of regression & 0,241320 & Akaike info criterion & \\
Sum squared resid & 160,4970 & Schwarz criterion & & 0,001330 \\
Log likelihood & 17,00239 & Hannan-Quinn criterion & & 0,042031 \\
F-statistic & 13,39855 & Durbin-Watson stat & \\
Prob(F-statistic) & 0,000000 & & & 0,016098 \\
\hline Resear & & & \\
\end{tabular}

Source: Researcher calculations.

According to the Akaike index amount, the optimal interruption for ARMA time series model of the TEDPIX (2 and 16) were selected. To ensure optimal results of entered interruptions in the model, the unit root structure of this series can be seen. In the following, the Arch effect in the TEDPIX model is studied.

Table 4. Evaluate the Arch effect in time series of the TEDPIX

\begin{tabular}{|c|c|c|c|c|}
\hline F-statistic & 40,30754 & \multirow{2}{*}{\multicolumn{2}{|c|}{$\begin{array}{c}\text { Prob.F(1,2772) } \\
\text { Prob.Chi-Square(1) }\end{array}$}} & 0,0000 \\
\hline Obs*R-squared & 39,75849 & & & 0,0000 \\
\hline Variable & Coefficient & Std.Error & $\mathrm{t}$-Statistic & Prob. \\
\hline $\mathrm{C}$ & 0,050921 & 0,002353 & 21,63930 & 0,0000 \\
\hline $\operatorname{RESID}^{\wedge} 2(-1)$ & 0,119721 & 0,018857 & 6,348822 & 0,0000 \\
\hline R-squared & 0,014333 & \multicolumn{2}{|c|}{ Mean dependent var } & 0,057847 \\
\hline Adjusted R-squared & 0,013977 & \multicolumn{2}{|c|}{ S.D.dependent var } & 0,110589 \\
\hline S.E. of regression & 0,109814 & \multicolumn{2}{|c|}{ Akaike info criterion } & $-1,579338$ \\
\hline Sum squared resid & 33,42782 & \multicolumn{2}{|c|}{ Schwarz criterion } & $-1,575064$ \\
\hline Log likelihood & 2192,542 & \multicolumn{2}{|c|}{ Hannan-Quinn criter } & $-1,577795$ \\
\hline F-statistic & 40,30754 & \multicolumn{2}{|c|}{ Durbin-Watson stat } & 2,015055 \\
\hline $\operatorname{Prob}($ F-statistic) & 0,000000 & & & \\
\hline
\end{tabular}

Source: Researcher calculations.

According to the results presented in Table 4 is considered that at the Arch effect model on time series data of the TEDPIX are seen. As a result, it is necessary that GARCH model according to the optimal interruption of the ARMA model is used. 
Table 5. Model Garch (symmetric mode) on the TEDPIX

\begin{tabular}{|c|c|c|c|c|}
\hline Variable & Coefficient & Std.Error & $\mathrm{t}-$ Statistic & Prob. \\
\hline $\mathrm{C}$ & 0,201669 & 0,018419 & 16,46740 & 0,0000 \\
\hline $\mathrm{AR}(1)$ & 0,458686 & 0,509552 & 0,900174 & 0,3680 \\
\hline $\mathrm{AR}(2)$ & 0,523819 & 0,536486 & 0,976389 & 0,3289 \\
\hline $\mathrm{AR}(3)$ & $-0,017724$ & 0,050010 & $-0,354411$ & 0,2230 \\
\hline $\mathrm{AR}(4)$ & 0,011443 & 0,029356 & 0,389799 & 0,6967 \\
\hline $\mathrm{AR}(5)$ & $-0,000110$ & 0,034126 & $-0,002542$ & 0,9967 \\
\hline $\mathrm{AR}(6)$ & $-0,074913$ & 0,024559 & $-2,235941$ & 0,0254 \\
\hline $\operatorname{AR}(7)$ & 0,039201 & 0,037578 & 1,043215 & 0,2968 \\
\hline $\mathrm{AR}(8)$ & 0,025255 & 0,044137 & 0,572196 & 0,5672 \\
\hline $\mathrm{AR}(9)$ & $-0,044066$ & 0,036843 & $-1,641606$ & 0,1007 \\
\hline $\operatorname{AR}(10)$ & 0,003176 & 0,030228 & 0,105062 & 0,9163 \\
\hline $\mathrm{AR}(11)$ & 0,002805 & 0,027409 & 0,102331 & 0,9185 \\
\hline $\mathrm{AR}(12)$ & 0,008058 & 0,024038 & 0,435224 & 0,7375 \\
\hline $\mathrm{AR}(13)$ & 0,014519 & 0,024975 & 0,581365 & 0,5610 \\
\hline $\mathrm{AR}(14)$ & $-0,027190$ & 0,02388 & $-1,138260$ & 0,2550 \\
\hline $\mathrm{AR}(15)$ & $-0,007532$ & 0,023433 & $-0,321443$ & 0,7479 \\
\hline $\mathrm{AR}(16)$ & 0,035741 & 0,021153 & 1,689644 & 0,0911 \\
\hline $\operatorname{MA}(1)$ & $-0,349613$ & 0,510242 & $-0,685191$ & 0,4932 \\
\hline $\operatorname{MA}(2)$ & $-0,542855$ & 0,481533 & $-1,127347$ & 0,2596 \\
\hline \multicolumn{5}{|c|}{ Variance Equation } \\
\hline $\mathrm{C}$ & 0,001659 & 0,000372 & 4,454433 & 0,0000 \\
\hline $\operatorname{RESID}(-1)^{\wedge} 2$ & 0,001659 & 0,000472 & 2,201084 & 0,0000 \\
\hline GARCH(-1) & 0,902852 & 0,013306 & 67,85439 & 0,0000 \\
\hline R-squared & 0,079273 & Mean dependent var & & 0,301610 \\
\hline Adjusted R-squared & 0,069916 & S.D.dependent var & & 0,250840 \\
\hline S.E. of regression & 0,241422 & Akaike info criterion & & $-0,073442$ \\
\hline Sum squared resid & 160,7054 & Schwarz criterion & & $-0,026442$ \\
\hline Log likelihood & 123,9004 & Hannan-Quinn criter & & $-0,056469$ \\
\hline Durbin-Watson stat & 1,970932 & & & \\
\hline
\end{tabular}

Source: Researcher calculations.

In addition, we have attempted to estimate the EGARCH equation.

Table 6. EGARCH model (asymmetric mode) on the TEDPIX

\begin{tabular}{ccccc}
\hline Variable & Coefficient & Std.Error & t-Statistic & Prob. \\
\hline C & 0,293776 & 0,019592 & 12,99325 & 0,0000 \\
AR(1) & 0,526398 & 0,571092 & 0,921739 & 0,3567 \\
AR(2) & 0,441372 & 0,596065 & 0,740477 & 0,3590 \\
AR(3) & $-0,008388$ & 0,051492 & $-0,162907$ & 0,8706 \\
AR(4) & 0,008248 & 0,029645 & 0,279170 & 0,7801 \\
AR(5) & 0,012171 & 0,023917 & 0,508865 & 0,6108 \\
AR(6) & $-0,058276$ & 0,025593 & $-2,277059$ & 0,0228 \\
AR(7) & 0,038737 & 0,044519 & 0,870122 & 0,3842 \\
AR(8) & 0,021747 & 0,047894 & 0,454058 & 0,6498 \\
AR(9) & $-0,045837$ & 0,026484 & $-1,730729$ & 0,0835 \\
AR(10) & 0,014010 & 0,032107 & 0,405199 & 0,6853 \\
AR(11) & 0,000647 & 0,030114 & 0,021498 & 0,9828 \\
AR(12) & 0,011042 & 0,024556 & 0,449641 & 0,6530 \\
AR(13) & 0,006154 & 0,025380 & 0,242454 & 0,8082 \\
AR(14) & $-0,027437$ & 0,024027 & $-1,141933$ & 02535 \\
AR(15) & $-0,002290$ & 0,023201 & $-0,098689$ & 0,9214 \\
AR(16) & 0,035645 & 0,021180 & 1,682995 & 0,0924 \\
MA(1) & $-0,421834$ & 0,572310 & $-0,737072$ & 0,3611 \\
MA(2) & $-0,465901$ & 0,536912 & $-0,867743$ & 0,3855 \\
\hline
\end{tabular}




\begin{tabular}{lrlrc}
\hline \multicolumn{1}{c}{ C(20) } & \multicolumn{3}{c}{ Variance Equation } \\
\multicolumn{1}{c}{ C(21) } & $-0,339861$ & 0,033687 & $-7,120291$ & 0,0000 \\
C(22) & 0,173351 & 0,020326 & 8,528402 & 0,0000 \\
\multicolumn{1}{c}{ C(23) } & $-0,014741$ & 0,014006 & $-1,052497$ & 0,2926 \\
\hline R-squared & 0,964738 & 0,007818 & 133,4011 & 0,0000 \\
Adjusted R-squared & 0,079271 & Mean dependent var & & 0,301610 \\
S.E. of regression & 0,074258 & S.D.dependent var & $-0,078837$ \\
Sum squared resid & 0,241477 & Akaike info criterion & $-0,029701$ \\
Log likelihood & 160,7057 & Schwarz criterion & $-0,061093$ \\
Durbin-Watson stat & 132,3869 & Hannan-Quinn criter & & \\
\hline
\end{tabular}

Source: Researcher calculations.

By comparing the results 4-5 and 4-6 are seen, given that the coefficients C (20) to C (23) are significant, as a result, estimation of the TEDPIX model on the EGARCH mode has explanatory power higher than the GARCH model.

In this section is presented the results of estimating the univariate MS-EGARCH $(1,1)$ model with fixed transition probabilities for TEDPIX. All parameters in the mean and variance functions are dependent on the period (regime) of expansion and recession (Change in different regimes is possible ). This means that the mean and variance are not static coefficients and are constantly changing. In fact, it would mean estimated non-linearity model of the TEDPIX; Because only in nonlinear models, the mean and variance of the coefficients from each data to another data is variable. One of the features of the offered MS-EGARCH models is the review of the regime changes and the asymmetry effects of ARCH simultaneously. Another feature of these models is that the features are not visible in different regimes, can be recognized in the estimation process and included in the estimate. This means that the factors that may cause changes in the regime but as an unpredictable variable has not been entered in the model can be detected and its effects included at the estimated model. At the estimated model of this study, asymmetry effects coefficients $\left(\delta_{1}\right.$ and $\left.\delta_{0}\right)$ have been diagnosed meaningful. Therefore, the results of study show asymmetric behavior among research data. These results in Table 7 are visible.

Table 7. Results of estimating the univariate MS-EGARCH $(1,1)$ for TEDPIX

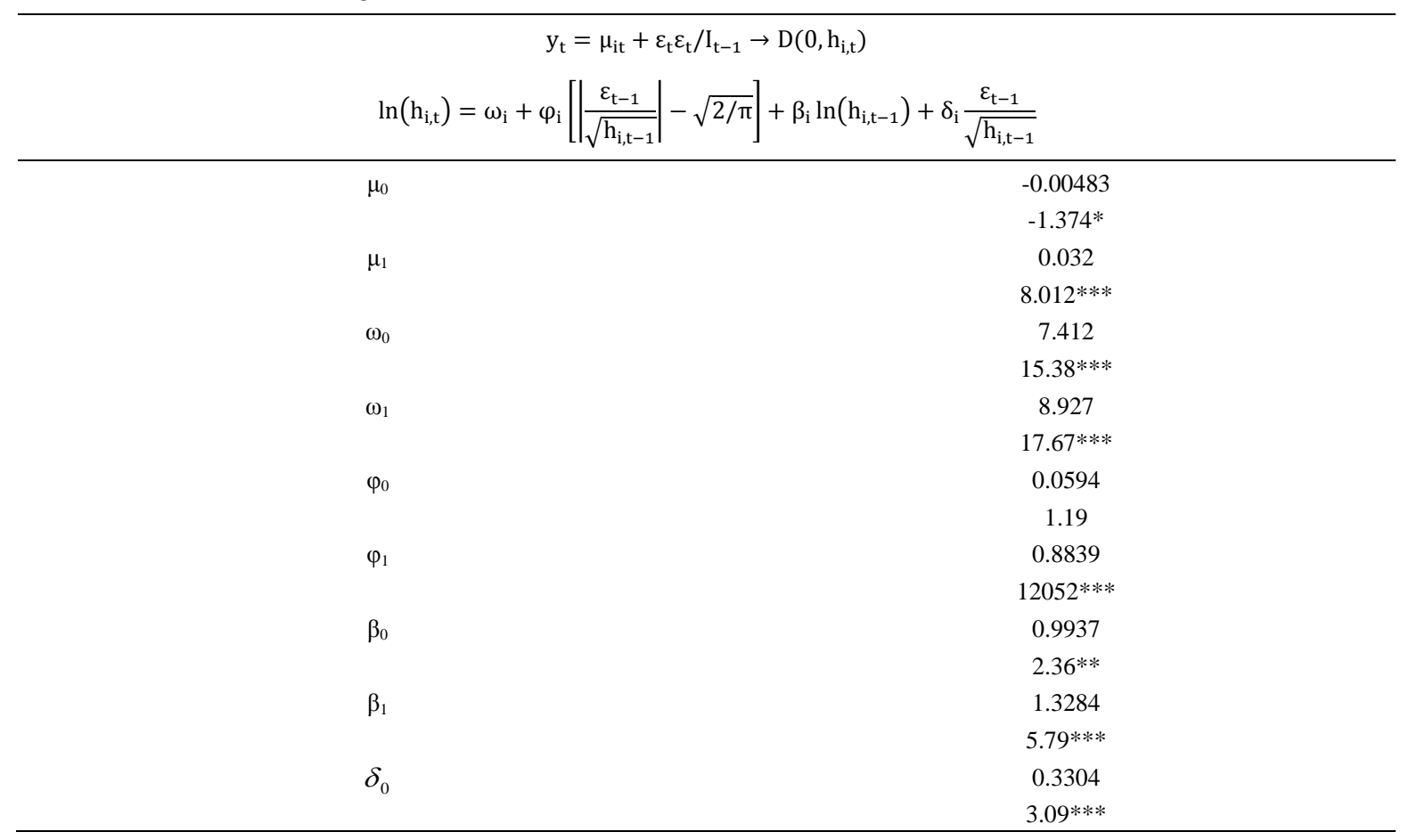




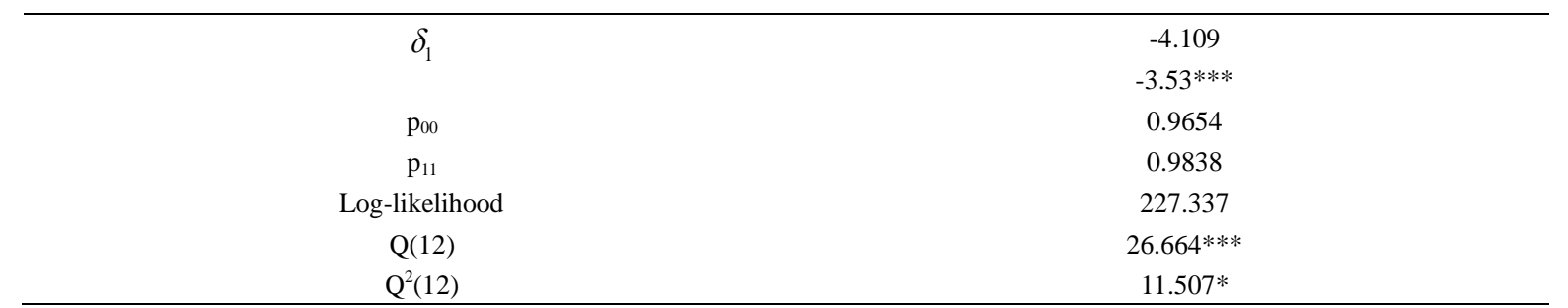

$* * *$ : meaningful at the $1 \%$ level.

**: meaningful at the $5 \%$ level.

*: meaningful at the $10 \%$ level.

Source: Researcher calculations.

Each of the specified regimes have a clear economic interpretation for the TEDPIX variable, accordingly, description of estimation results which are presented in Table 7, is as follows:

1) Based on the results of the estimation, two regimes has been detected. In the first regime, the behavior of the TEDPIX has been detected in a recession with low volatility and in the second regime, the behavior of the TEDPIX has been detected in an expansion with high volatility.

2) Based on the results of the average assessment model, the conditional variance and constant term (intercept) of the 1 regime is higher than 0 regime. The average of returns changes in during the recession $(\mu 0)$ for every 5 minutes has been estimated equal to -0.0048 that is significantly different from zero. In addition, in the 1 regime, its value $(\mu 1)$ is equal to 0.032 .

3) In order to determine which regime is more stable, evaluation and comparison of the estimated probabilities is required. Based on the estimation results of transition probabilities p00 and p11, both for changes of Exchange returns are quite meaningful. According to the probabilities results, remaining at the 0 regime ( $\mathrm{p}_{00}$ is approximately 0.9654 percent) is smaller than the chance to remain in 1 regime $\left(\mathrm{p}_{11}\right.$ is in about 0.9838 percent), and the magnitude of these possibilities implies that only a major event could transfer Exchange returns from 1 regime to 0 regime (and vice versa). In the following, we will study the effect of the stock trading shocks by large and small companies on the changes behavior of the Exchange returns in recession and expansion regimes.

In this section, variable of stock trading by large and small companies is separately entered in the average function and variance of MS-EGARCH model. The main objective is to evaluate whether stock trading by large and small companies are linked to changes in Exchange returns and whether the behavior changes in Exchange returns with entering this variable can be explained or not? For this purpose, MS-EGARCH model with fixed transition probabilities were developed. In order to determine whether the shocks of stock trading by large and small companies on the returns changes affect or not? The value of verisimilitude of the two models in the presence or absence of the stock trading shock by large companies were compared that their results in Table 8 are presented.

Table 8. LR test, evaluate the effect or no effect of the variable of first interval of stock trading by large companies on the changes of Exchange returns

\begin{tabular}{rrr}
\hline & $\operatorname{lnL}$ & LR \\
\hline univariate MS-EGARCH(1,1) & 227.337 \\
MS-EGARCH(1,1) with inclusion of first interval of the stock trading by large companies & 238.262 & $\chi^{2}=21.85^{* * *}$ \\
\hline
\end{tabular}

***: meaningful at the $1 \%$ level.

Source: Researcher calculations.

The test results reveal that the model MS-EGARCH $(1,1)$ with inclusion of shock variable of the stock trading by large companies and fixed transmission probabilities compared to univariate MS-EGARCH $(1,1)$ model has a higher verisimilitude rate (238.262 is larger than 227.337) and univariate MS-EGARCH $(1,1)$ model is rejected at a meaningful level of 1 percent. These findings provide evidences based on meaningful impact of the stock trading shocks by large companies on the returns changes in stock market. This time, value of verisimilitude of the two models in the presence or absence of the stock trading shock by small companies were compared that their results in Table 9 are presented. 
Table 9. LR test, evaluate the effect or no effect of the variable of first interval of stock trading by small companies on the changes of exchange returns

\begin{tabular}{ccc}
\hline & $\operatorname{lnL}$ & LR \\
\hline $\begin{array}{c}\text { univariate MS-EGARCH(1,1) } \\
\text { MS-EGARCH(1,1) with inclusion of first interval of the stock trading by small } \\
\text { companies }\end{array}$ & 227.337 & 227.362 \\
\hline
\end{tabular}

$* * *$ : meaningful at the $1 \%$ level.

Source: Researcher calculations.

The test results reveal that the model MS-EGARCH $(1,1)$ with inclusion of shock variable of the stock trading by small companies and fixed transmission probabilities compared to univariate MS-EGARCH $(1,1)$ model has a higher verisimilitude rate (227.362 is larger than 227.337) and univariate MS-EGARCH $(1,1)$ model is not rejected at a meaningful level of 1 percent. These findings don't provide evidences based on meaningful impact of the stock trading shocks by small companies on the returns changes in stock market.

So, shocks of the stock trading by large companies in the Exchange returns in the regimes of expansion and recession will be studied. At table (10), the estimation results of the MS-EGARCH(1,1) model with fixed transition probabilities have been calculated.

Table 10. Results of estimating the MS-EGARCH $(1,1)$ model with inclusion of first interval of the stock trading by large companies

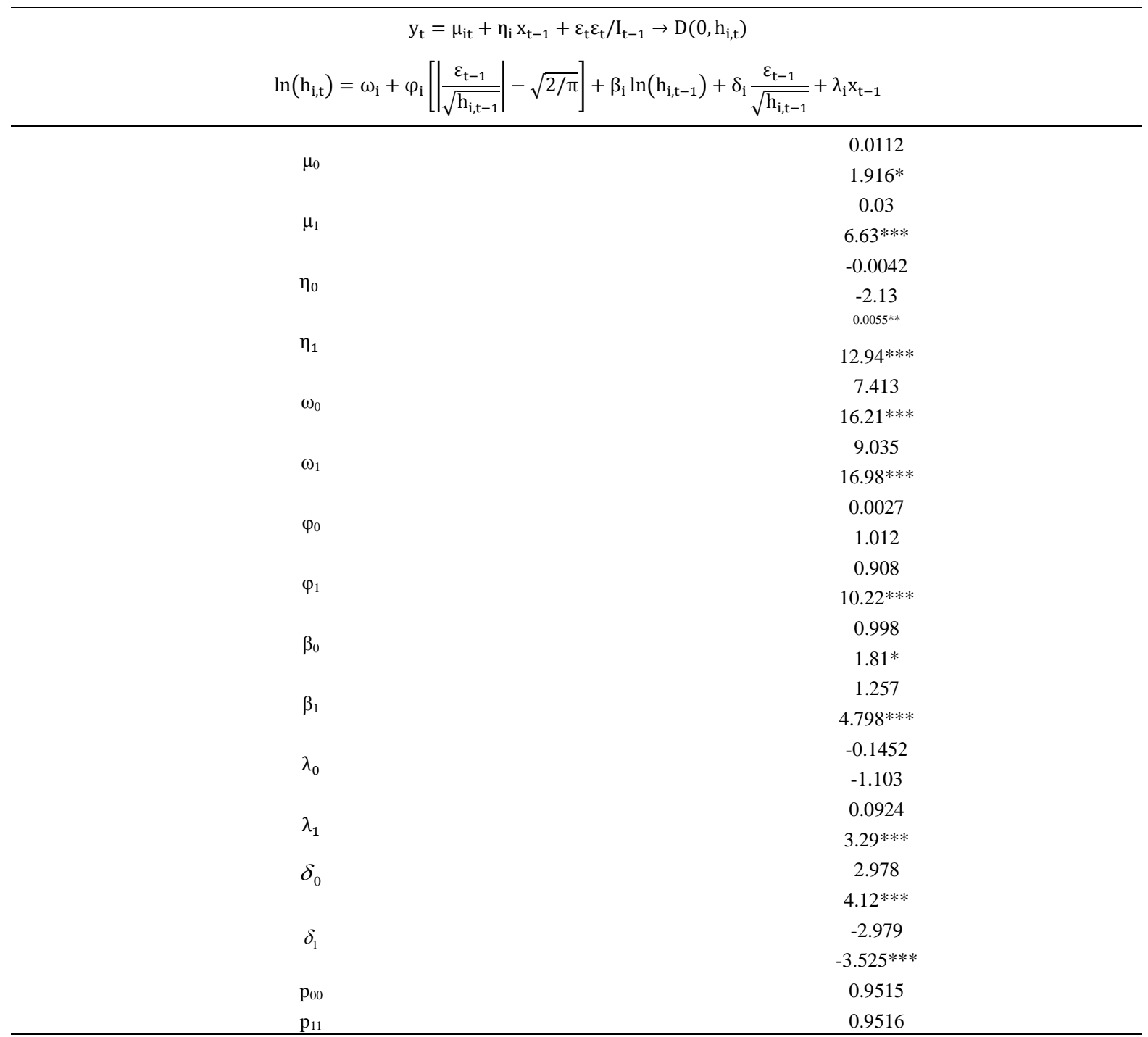




\begin{tabular}{cc}
\hline Log-likelihood & 238.262 \\
$\mathrm{Q}(12)$ & $23.518^{* * *}$ \\
$\mathrm{Q}^{2}(12)$ & $9.78^{*}$ \\
\hline
\end{tabular}

***: meaningful at the $1 \%$ level.

**: meaningful at the $5 \%$ level.

$*$ : meaningful at the $10 \%$ level.

Source: Researcher calculations.

The estimation results for the model in the 0 regime (associated with low variance regime and by large companies is significantly different from zero, this means that entering this variable has increased the explanatory power to interpret reason of the changes in Exchange returns. These effects in the 0 regime are negative and in the 1 regime, positive. The estimation results indicate that in the low average and variance regimes (recession), stock trading shocks by large companies have a negative effect on Exchange return changes $\left(\eta_{0}=-0.0042\right)$ and no low average) and the 1 regime (associated with high variance and high average) in Table (10) is provided. Based on results of the Table 10, the estimated coefficients of the stock trading shock meaningful effect on the variance of Exchange return changes. But, in the high average and variance regimes (expansion), it has the positive and meaningful effect on the both of variance and average level of Exchange return changes $\left(\eta_{1}=0.0055, \lambda_{1}=0.0924\right)$ The above results show asymmetric effects of stock trading by large companies on the Exchange returns changes in the expansion and recession regimes. It should be noted that based on conducted calculations, the turnover of small companies do not have a meaningful effect on the Exchange returns; Therefore, evaluate the MS-EGARCH model with fixed transmission possibilities in the small companies has been ignored.

\section{Conclusion and Recommendations}

In this study, we looked at the impact of high frequency trading on stock returns of large and small companies in the Tehran Stock Exchange during the last two years (1392-1393). Based on the LR test, it was concluded that evaluation of variable trend of the stock returns changes in non-linear mode (separation of period duration to the expansion and recession periods) on linear mode (no separation of period to the expansion and recession periods) is preferred.

Provided MS-EGARCH $(1,1)$ model with inclusion of stock trading variable by large companies shows a strong dependency between stock returns changes to the stock trading by large companies in various regimes. In other words, the estimated coefficients of the stock trading variable by large companies in the estimated model is significantly different from zero. These effects in the 0 regime are positive and in the 1 regime, negative.

Based on the estimation results in the low average and variance regimes (recession), stock trading shocks by large companies have a negative effect on Exchange return changes and have no meaningful effect on the variance of Exchange return changes. In other words, when the volatility in stock trading by large companies is small leads to changes in average of Exchange returns, but has no significant effect on the Exchange returns variance. In fact, small volatility in stock trading by large companies will not lead to drastic changes in Exchange returns and market stability will not be affected much. It is worth noting that volatility in stock trading by large companies in the low average and variance regime (recession regime $=$ low volatility) in the increase and decrease mode of stock trading by large companies will have a different impact on Exchange returns changes and the generally positive effect of this volatility on Exchange market returns is greater than its negative effects.

In the high average and variance regime (expansion regime - high volatility), entering stock trading variable by large companies leads to an increase in variance and average Exchange return changes simultaneously that will make instability in the Exchange market. Also, the results show asymmetric effects of stock trading by large companies on the Exchange returns changes in expansion regime. It is worth noting that volatility in stock trading by large companies in the high average and variance regime, in the increase and decrease mode of stock trading by large companies will have a different impact on Exchange returns changes and the generally its positive effects is smaller than its negative effects. In other words, the high increase in stock trading by large companies compared with reduction of stock trading by large companies will have less impact on changes in stock returns. Accordingly in the present study, high-frequency trading were divided into two categories: large and small frequencies, and it was found that high-frequency trading with large amplitude have significant effect on emotional behavior in Tehran Stock Exchange.

The results of this study are in line with the research of Alavi and Jamazi (2010), Yu and Nie (2009), Flavin et al. 
(2008) and Valid et al. (2011) and also Pedram (1389). In other words, results of the present study similar to the results of this investigation showed that these conditional volatility are provided under different regimes. The reason for this can be found in the nature of turbulent financial markets. These markets for follow-up of psychological factors, often show sensitivities more than what is necessary for the re-stability of this market.

Su and Yu (2006), Rai et al. (1393) and Shams (1389) in their research like the present research knows EGARCH method better than GARCH method to predict stock volatility in the stock Exchange that because of the asymmetry is TEDPIX.

Given that the stock returns volatility is separable into two different regimes, policymakers can implement different policies in accordance with characteristics of the regime. Also, due to the impact of large companies behavior on Exchange total returns, active investors by controlling their emotional behavior is necessary to prevent the further instability in Exchange market.

\section{References}

Abounoori, I., \& Motameni, M. (1385). Evaluation simultaneously leverage effect and feedback volatility in the Tehran Stock Exchange. Economic Research Journal, (76), 101-117.

Akgiray, A. (1989). Conditional heteroskedasticity in time series of stock returns: Evidence and forecasts. Journal of Business, 62(1), 55-80. http://dx.doi.org/10.1086/296451

Al Omran, S. A., \& Al Omran, R. (1391). Evaluate the volatility trend in the Tehran Stock Exchange. Quarterly of Scientific- Research, Financial Knowledge Analysis Stock, (14), 119-132.

Aloui, C. (2007). Price and volatility spillovers between exchange rates and stock indexes for the pre- and post-euro period. Quantitative Finance, 7, 1-17. http://dx.doi.org/10.1080/14697680701302653

Aloui, C., \& Jammazi, R. (2010). The Effects of Crude Oil Shocks on Stock Market Shifts Behavior: A Regimes Witching Approach. Energy Economics, 31(5), 789-799. http://dx.doi.org/10.1016/j.eneco.2009.03.009

Beshiri, M. N., \& Mashayekh, S. (1385). Performance of added value measure of economic in the Tehran Stock Exchange. Accounting Journal, (173), 12-15.

Bollerslev, T. (1986). Generalized Autoregressive Conditional Heteroskedasticity. Journal of Econometrics, 31, 307. http://dx.doi.org/10.1016/0304-4076(86)90063-1

Campbell, J. Y., \& Ludger, H. (1992). No News is Good News: An Asymmetric Model of Changing Volatility in Stock Returns. Journal of Financial Economics, (31), 281-318. http://dx.doi.org/10.1016/0304-405X(92)90037-X

Choudry, T. (1996). Stock Market Volatility and the Crash of 1987: Evidence from Six Emerging Markets. Journal of International Money and Finance, (15), 969-981. http://dx.doi.org/10.1016/S0261-5606(96)00036-8

Corradi, V., \& Distaso, W. (2009). Macroeconomic Determinants of Stock Market Volatility and Volatility RiskPremiums. Retrieved from http://ssrn.com

Delavari, M., \& Rahmati, Z. (1389). Evaluate the variability of the price of gold coins in Iran using ARCH models. Knowledge and Development, 17(30), 51-68.

Fallah, S. M. (1389). Evaluate the performance comparison of risk assessment model and GARCH econometric model to predict the market risk in the Tehran Stock Exchange. Financial Engineering and Management of Portfolios Journal, (5), 137-159.

Fallahpour, S., Rezvani, F., Rahimi, M. R. (1394). Estimate the value at CVaR conditional risk using symmetric and asymmetric conditional heteroskedasticity models in gold and oil market. Quarterly of ScientificResearch, Financial Knowledge Analysis Stock, 8(26), 1-18.

Flavin, T. J., Panopoulou, E., \& Unalmis, D. (2008). On the stability of domestic financial market linkages in the presence of time-varingvolatility. Emerging Markets Review, 9, 280-301. http://dx.doi.org/10.1016/j.ememar.2008.10.002

Henry, O. (2009). Regime switching in the relationship between equity returns and short-term interest rates. Journal of Banking and Finance, 33(2), 405-414. http://dx.doi.org/10.1016/j.jbankfin.2008.08.001

Karunanayake, I., \& Valadkhani, A. (2009). Modelling Australian Stock Market Volatility: A Multivariate GARCH Approach. University of Wollongong, Economics Working Paper Series.

Li, H., \& Majerowska, E. (2007). Testing stock market linkages for Poland and Hungary: A multivariate GARCH 
approach. Research in International Business and Finance, 22(2008), 247-266.

Morelli, D. (2002). The relationship between conditional stock market volatility Empirical evidence based on UK data. International Review of Financial Analysis, (11), 101-110. http://dx.doi.org/10.1016/S1057-5219(01)00066-7

Namazi, M., \& Nazemi, A. (1384). Analysis of conducted research at the Stock Exchange. Financial Research Journal, (19), 135-166.

Noferesti, M. (1391). Unit root and co-integration in econometrics (4th ed., p. 132). Rasa Publishing.

Pedram, M. (1391). Effect of exchange rate fluctuations on the Iran stock market volatility. Quarterly of financial knowledge Analysis Stock, (15), 83-97.

Poon, S., \& Granger, C. W. J. (2003). Forecasting Volatility in Financial Markets: A Review. Journal of Economic Literrature, 41, 478-539. http://dx.doi.org/10.1257/.41.2.478

Rai, R., Mohammadi, S., \& Saranj, A. (1393). Evaluate the dynamics of the Tehran Stock Exchange using the EGARCH-M model in Markov switching average. Financial Research, 16(15), S77-98.

Ramzyari, B., \& Dadgar, Y. (1391). Experimental test of stability, predictability and volatility in the capital markets of the Persian Gulf countries. Economic Modeling, (16), 1-20.

Rufus, A. O. (2009). Stock Return, Volatility and The Global Financial Crisis in An Emerging Market: The Nigerian Case. International Review of Business Research Papers, (4), 426-447.

Samadi, S., \& Bayani, O. (1390). Evaluate the relationship between macroeconomic variables and stock returns in the Tehran Stock Exchange. Quarterly of Finance, 5(16), 91-112.

Slepaczuk, R., \& Zakrzewski, J. (2010). High Frequency and Model-FreeVolatility Estimators. Conference Paper- $17^{\text {th }}$ International Conference.

So, M. K. P., \& Yu, P. L. H. (2005). Emprical analysis of Garch models in Value at Risk Estimation. International Financial Markets, Institutions and Money, 16, 180-197. http://dx.doi.org/10.1016/j.intfin.2005.02.001

Suri. (1392). The functions and role of the stock Exchange in the economy. Zakhire Shahed Company (stock expert).

Taghavi, M., Ghaffari, F., \& Gheybi, S. Y. (1389). The effect of the financial crisis the West over Tehran stock Exchange. Journal of Financial Studies, financial knowledge, Analysis Stock, 3(5), S137-160.

Taylor, S., \& Areal, N. M. P. C. (2002). The realized volatility of FTSE-100 futures prices. Journal of Future Markets, 22, 627-648. http://dx.doi.org/10.1002/fut.10018

Walid, C., Chaker, A., Masood, O., \& Fry, J. (2011). Stock market volatility and exchange rates in emerging countries: A Markov-state switching approach. Emerging Markets Review, 12, 272-292. http://dx.doi.org/10.1016/j.ememar.2011.04.003

Wang, X. F. (2011). The Relationship between Stock Market Volatility and Macroeconomic Volatility: Evidence from China. Journal of Chinese Economics and Fianance, 2, 67-77.

Yau, H. Y., \& Nieh, C. C. (2009). Testing for cointegration with threshold effect between stock prices and exchange rates in Japan and Taiwan. Japan and World Economy, 21, 292-300. http://dx.doi.org/10.1016/j.japwor.2008.09.001

\section{Copyrights}

Copyright for this article is retained by the author(s), with first publication rights granted to the journal.

This is an open-access article distributed under the terms and conditions of the Creative Commons Attribution license (http://creativecommons.org/licenses/by/3.0/). 